\title{
Impacts of the thawing-freezing process on runoff generation in the Sources Area of the Yellow River on the northeastern Qinghai-Tibet Plateau
}

\author{
Xiaoling $\mathrm{Wu}^{1}$, Xiaohua Xiang ${ }^{1}$, Chao Qiu ${ }^{2}$, and $\mathrm{Li} \mathrm{Li}^{3}$ \\ ${ }^{1}$ College of Hydrology and Water Resource, Hohai University, Nanjing 210098, China \\ ${ }^{2}$ Zhejiang Provincial Hydrology Burean, Hangzhou 310009, China \\ ${ }^{3}$ Jiangsu Province Water Engineering Sci-tech Consulting. Corp.Ltd, Nanjing 210009, China
}

Correspondence: Xiaohua Xiang (freebir7237@hhu.edu.cn)

Received: 31 December 2017 - Revised: 9 April 2018 - Accepted: 14 April 2018 - Published: 5 June 2018

\begin{abstract}
In cold regions, precipitation, air temperature and snow cover significantly influence soil water, heat transfer, the freezing-thawing processes of the active soil layer, and runoff generation. Hydrological regimes of the world's major rivers in cold regions have changed remarkably since the 1960s, but the mechanisms underlying the changes have not yet been fully understood. Using the basic physical processes for water and heat balances and transfers in snow covered soil, a water-heat coupling model for snow cover and its underlying soil layers was established. We found that freezing-thawing processes can affect the thickness of the active layer, storage capacity for liquid water, and subsequent surface runoffs. Based on calculations of thawing-freezing processes, we investigated hydrological processes at Qumalai. The results show that the water-heat coupling model can be used in this region to provide an understanding of the local movement of hydrological regimes.
\end{abstract}

\section{Introduction}

Recently, the earth system has been influenced by permafrost and glacier evolvement. The area of China's seasonally frozen soil region is $5.137 \times 10^{6} \mathrm{~km}^{2}$, with an additional $2.068 \times 10^{6} \mathrm{~km}^{2}$ as permafrost. This accounts for $75 \%$ of China's total land area (Xu and Deng, 1991). Investigation of permafrost hydrology is important for local ecosystem security and human life. The extensive collection of field measurement data during the last decades has increased considerably, including the available information on hydro-meteorological processes in cold regions, but most of these data are too fragmentary.

Frozen soil plays an important role in the hydrology of cold regions (Harris et al., 2009). Many studies on frozen soil have been conducted. The SHAW model incorporates land surface processes to describe the snow-melting effect and the freezing-thawing process in a one-dimensional study (Flerchinger and Saxton, 1989). The most important part of this kind of model is the connection between coupled mechanisms. Snow cover greatly affects the heat and water transfer to the underlying soil. Thus, soil water-heat movements and snow cover conditions have important theoretical value (Jorgenson et al., 2001; Harris et al., 2001; Heginbottom, 2002; Romanovsky and Osterkamp, 2001).

The coupled, dynamic model developed in this paper, using snow cover and frozen soil together, sets the connection between snow cover and soil and demonstrates an association between snow cover and soil.

\section{Methods}

The snow-soil coupled model established in this paper comprises a snow cover: water and heat movement model and a frozen soil: water-heat coupled movement model.

\subsection{Snow cover model}

On the basis of conservation of energy (Xu and Li, 2003), the net heat flux of snow cover is equal to the intersystem heat increase over the same interval. The snow exchanges energy with the atmosphere above and ground below. The net energy 
flux of the snowpack can be expressed as

$Q_{\text {net }}=Q_{\mathrm{r}}+Q_{\mathrm{s}}+Q_{1}+Q_{\mathrm{p}}+Q_{\mathrm{g}}$

where $Q_{\text {net }}$ is net input energy for snowpack $\left(\mathrm{J} \mathrm{m}^{-2}\right) ; Q_{\mathrm{r}}$ is the net radiation flux $\left(\mathrm{W} \mathrm{m}^{-2}\right) ; Q_{\mathrm{s}}$ is flux of sensible heat $\left(\mathrm{W} \mathrm{m}^{-2}\right) ; Q_{1}$ is flux of latent heat $\left(\mathrm{W} \mathrm{m}^{-2}\right) ; Q_{\mathrm{p}}$ is heat flux supplied by precipitation $\left(\mathrm{W} \mathrm{m}^{-2}\right) ; Q_{\mathrm{g}}$ is ground heat flux $\left(\mathrm{W} \mathrm{m}^{-2}\right)$ always being neglected.

Based on the water balance, daily snow melt was estimated using the net energy of the snow cover.

The snow melt can be divided into three phases: warming, ripening and output (Dingman, 1994).

$W_{\text {liq }}=W_{\text {liq }}+\left(P_{\mathrm{r}} E+\Delta W\right)$

$W_{\mathrm{s}}=W_{\mathrm{s}}+\left(P_{\mathrm{s}} S \Delta W\right)$

where $W_{\text {liq }}$ is liquid water content $(\mathrm{m}) ; W_{\mathrm{s}}$ is snow water equivalent (m); $\Delta W$ is the energy for water transfer; $P_{\mathrm{S}}$ is snowfall $(\mathrm{m}) ; S$ is sublimation $(\mathrm{m}) ; E$ is evaporation (m); $C_{i}$ is heat capacity of snow $\left(\mathrm{J} \mathrm{kg}^{-1 \circ-1}\right)$; $\lambda_{\mathrm{f}}$ is latent heat of fusion $\left(\mathrm{kJ} \mathrm{kg}^{-1}\right)$.

When $W_{\text {liq }}$ is larger than the holding capacity of the snow cover, the outflow from the snow cover is described as

$W_{\text {out }}=W_{\text {liq }}-W_{\text {liq_max }}$

where $W_{\text {liq_max }}$ is the holding capacity of the snow cover $(\mathrm{m})$ and $W_{\text {out }}$ is the outflow from the snow cover $(\mathrm{m})$.

\subsection{The frozen soil water-heat coupled movement model}

We hypothesized the following assumptions could be applied to our model, including the influence of soil water vapor migration and heat flow transfer can be ignored; the soil is considered vertical and non-plastic soil; vertical heat and moisture flux; and Darcy's law applies to moisture movement in both saturated and unsaturated conditions (Shoop and Bigl, 1996). Based on these assumptions, water and heat movement in seasonally frozen soil can be treated as a onedimensional problem.

Water movement in freezing and thawing soil can be expressed as Richard's equation and a one-dimensional heat transport equation for a freezing or thawing column of soil.

$C_{\mathrm{s}} \frac{\partial T}{\partial t}=\frac{\partial}{\partial Z}\left(\lambda \frac{\partial T}{\partial Z}\right)+L_{\mathrm{f}} \rho_{i} \frac{\partial \theta_{i}}{\partial t}$

$\frac{\partial \theta_{1}}{\partial t}=\frac{\partial}{\partial Z}\left(D\left(\theta_{1}\right) \frac{\partial \theta_{1}}{\partial Z}-K\left(\theta_{1}\right)\right)-\frac{\rho_{i}}{\rho_{1}} \frac{\partial \theta_{i}}{\partial t}$

where $D\left(\theta_{1}\right)$ is the diffusivity of soil $\left(\mathrm{m}^{2} \mathrm{~s}^{-1}\right) ; K\left(\theta_{1}\right)$ is unsaturated hydraulic conductivity of soil $\left(\mathrm{m} \mathrm{s}^{-1}\right) ; \rho_{\mathrm{s}}$ is density of ice $\left(\mathrm{kg} \mathrm{m}^{-3}\right) ; \rho_{1}$ is density of liquid water $\left(\mathrm{kg} \mathrm{m}^{-3}\right) ; \theta_{1}$ is

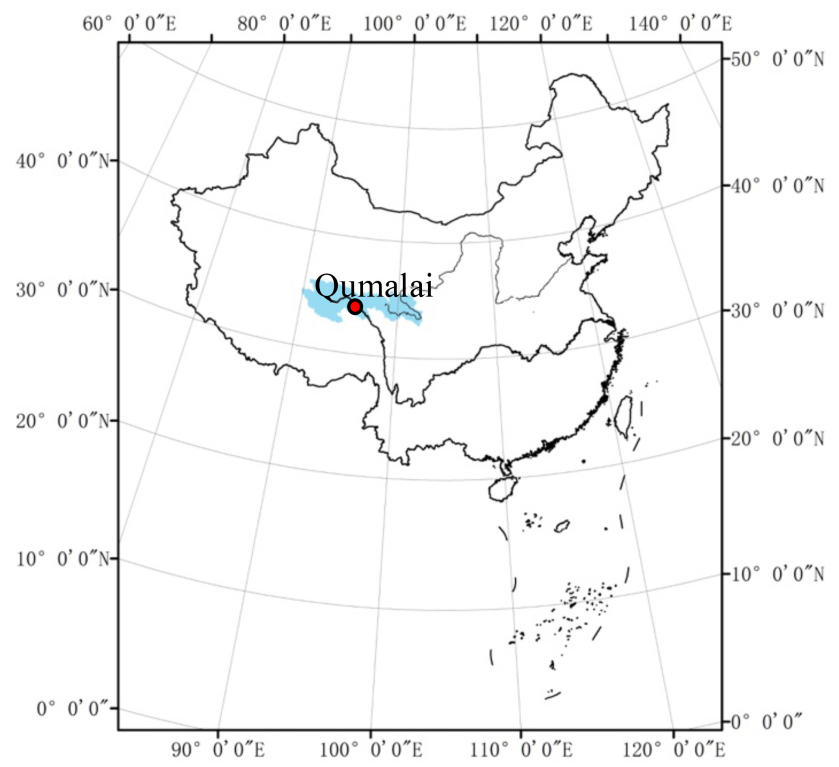

Figure 1. Distribution of observation site in the Three-River Source Region.

volumetric liquid water content $(\%) ; \theta_{\mathrm{S}}$ volumetric ice content (\%); $C_{\mathrm{s}}$ is volumetric heat capacity of soil $\left(\mathrm{J} \mathrm{m}^{-3 \circ-1}\right) ; \lambda$ is thermal conductivity of soil $\left(\mathrm{W} \mathrm{m}^{-1 \circ-1}\right) ; L_{\mathrm{f}}$ is latent heat of fusion $\left(\mathrm{J} \mathrm{kg}^{-1}\right) ; T$ is soil temperature $\left(^{\circ}\right) ; Z$ is depth (m); $t$ is time (s).

\subsection{Coupled model}

Based on the water balance, the water content $\theta_{1 \_ \text {top }}$ in the top layer of soil relied on the outflow from snow pack $W_{\text {out }}$, and evaporation from soil surface $E_{\text {soil }}$, the liquid content in top soil layer was given by

$\theta_{\text {l_top }}=\beta\left(W_{\text {out }}-E_{\text {soil }}\right)$

where $\beta$ is the constant coefficient.

\section{Study site}

The observation site selected for this study, Qumalai $\left(34.13^{\circ} \mathrm{N}, 95.78^{\circ} \mathrm{E}\right)$, is located in the middle of the ThreeRiver Source Region. The average elevation of Qumalai is $4500 \mathrm{~m}$ (Fig. 1). Controlled by the high altitude and pressure, the climate in Qumalai includes strong radiation, long light duration and seasonal variations for warm (four or five) months and cold (seven or eight) months. The mean annual air temperature is $-3.3^{\circ}$. The mean annual precipitation is 380-470 mm. (Yin et al., 2010).

The atmospheric data used in this study includes hourly precipitation, air temperature, relative humidity, wind velocity, hours or daylight and atmospheric pressure. Daily snow thickness, soil freezing depths, soil temperature at depth of 


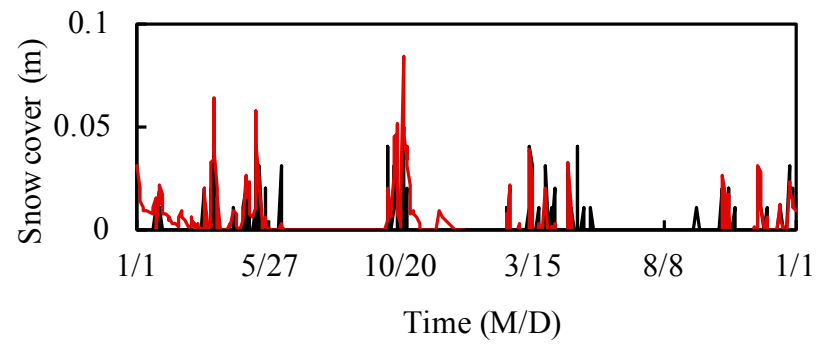

Figure 2. Comparison between simulated (red solid line) and measured (black solid line) results for the thickness of snow cover from 2005 to 2006.

$15 \mathrm{~cm}$ and soil water content at the depth of $50 \mathrm{~cm}$ were monitored from 2005 to 2006.

Permafrost and seasonal frozen soil is widely distributed throughout the study area. Because of the presence of frozen soil, water retention in the soil can be enhanced for both rain and snow melt compared to soils in non-frozen or temperate regions. The permafrost dynamics greatly influence the hydrologic processes (McGuire, 2002; Walker et al., 2003).

\section{Results}

\subsection{Snow depth}

Observation of air temperature, snow surface temperature, humidity, rainfall, wind velocity, atmospheric pressure and hours of daylight provided a good dataset for driving the snow cover model. Comparisons between simulated and measured results for snow depth in 2005-2006 are shown in Fig. 2.

According to Fig. 2, the snow depth trends were the same for both the simulated results and the measured values. At Qumalai, snow accumulation was measured from late October through the middle of May the following year, when the melting process finished. Between mid-March and early November, the snow depth reached a maximum.

\subsection{Freezing depth}

The daily mean freezing depth was used in the following analysis. Figure 3 shows the depth of frozen soil from October 2005 to June 2006. The simulation of the frozen soil trend for the whole period was consistent with measurements.

The daily mean soil temperature grew progressively colder in October, and the surface soil began to freeze at the same time. Over time, the soil froze deeper, and after 141 days (11 March), it was frozen to $95 \mathrm{~cm}$.

The majority of the site began to thaw in April, when temperatures grew warmer. The shallow layer of soil began thawing on 15 March. By early April, the layer below $140 \mathrm{~cm}$ also began to thaw, though the layers between 70 and $140 \mathrm{~cm}$

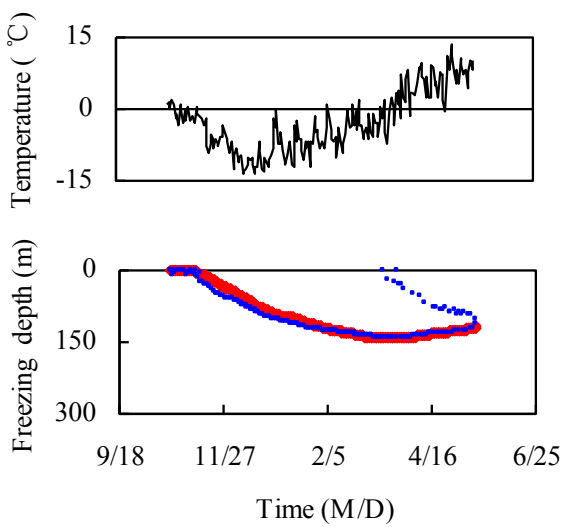

Figure 3. With the observed soil surface temperature at the corresponding times, the comparison between measured (red dashed line) and simulated (blue dashed line) freezing depth of soil from October 2005 to June 2006.

depth remained frozen. The remaining frozen soil thawed from both the top and bottom depths.

\subsection{Soil temperature}

Figure 4 shows the simulated and measured daily average temperatures for every day of 2005-2006. According to Fig. 4, both the simulated and measured soil temperatures show the same trend. The soil temperature warmed from late March into late October, which corresponds to when the soil thawed (Fig. 3).

To detect the numerical model efficiency, efficiency coefficients (EC) and root mean squared errors (RMSE) were used. RMSE for simulated daily soil temperatures of 2005-2006 ranged from 1.82 to $1.9^{\circ}$, and EC was 0.94 . There was no distinct difference for the surface soil. This means that there was no system error for the model used at these sites, and the simulated temperature for surface soil was coincident with the measured value.

\subsection{Soil water content}

Soil liquid water content was measured at $50 \mathrm{~cm}$ from April to October 2005 at Qumalai. The comparisons between simulated and measured results are shown in Fig. 5.

The simulated liquid water content decreased in early May, when there was heavy evaporation and no precipitation. As the evaporation decreased, the liquid water content increased, while precipitation created an increase in soil moisture.

From the simulation results, we found that during the thawing period, the soil liquid water content was significantly affected by the surface conditions, including precipitation and evaporation. 

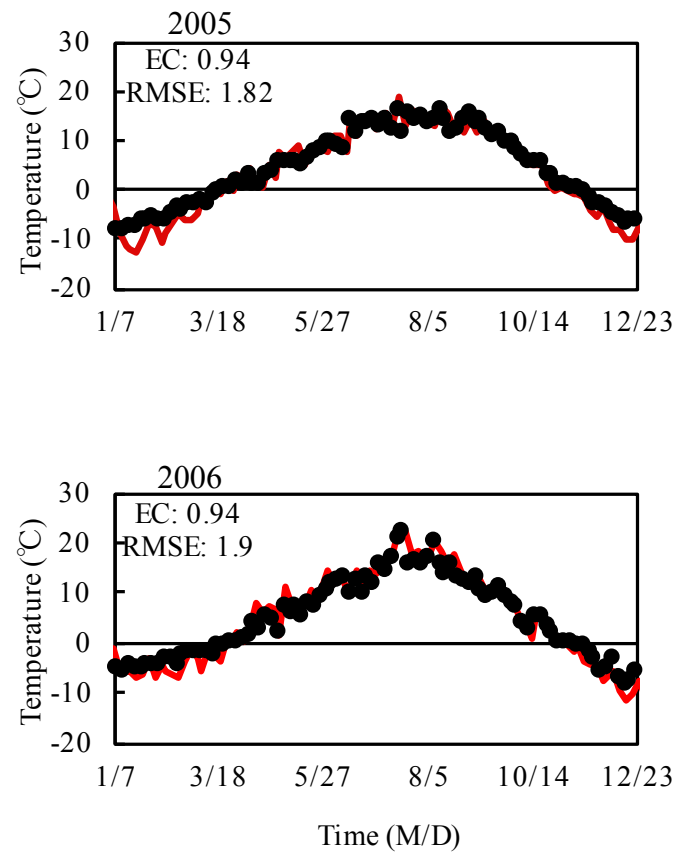

Figure 4. Comparison between simulated (red solid line) and measured (black dashed line) results for soil temperature at $15 \mathrm{~cm}$ depth in 2005-2006.
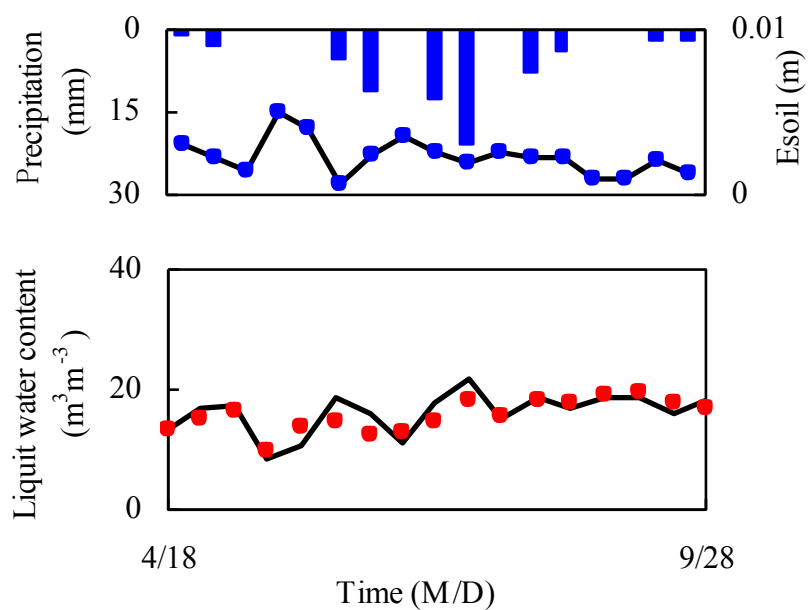

Figure 5. With the observed precipitation (blue bar) and simulated evaporation (black solid line with blue circle) at the corresponding time, comparison between simulated (black solid line) and measured (red dotted line) results for soil liquid water content at $50 \mathrm{~cm}$ depth in 2005.

\subsection{Runoff}

\subsubsection{In soil thawing period}

In most parts of the Three-River Source Region, the liquid water storage capacity gradually increased as the soil water phase changed from ice to liquid. The thawing process
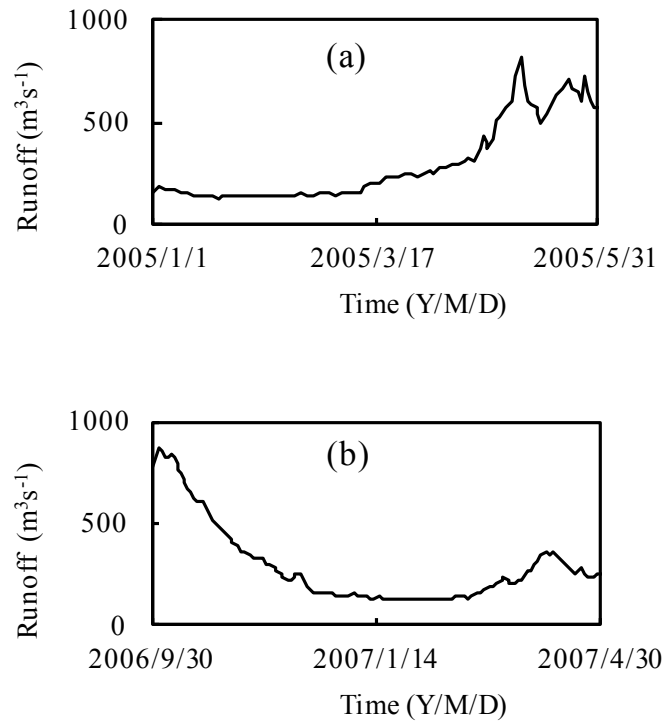

Figure 6. Runoff in the Yellow-River Source Region from 2005 to 2007. The study was carried out during the thawing (March to April) and freezing (October to March) periods.

caused the unsaturated soil status and snowmelt filtration. Runoff from the Yellow-River Source Region did not vary very much until late April, when the soil was completely thawed (Fig. 6a).

\subsubsection{In soil freezing period}

Runoff fluctuated between 124 and $240 \mathrm{~m}^{3} \mathrm{~s}^{-1}$, resulting from increased air temperature, evaporation and snowmelt. Runoff increased suddenly in mid-December 2006 (Fig. 6b) because of the high air temperature and deep frost depth. Based on the above analysis, the main factors affecting runoff during the frozen soil period are air temperature, evaporation and frozen soil, which stops further penetration of liquid water causing it to runoff.

During the later period of frozen soil, especially from late February to mid-March 2007, the runoff increased. This was due to the frozen soil and increasing precipitation and air temperature.

\section{Conclusions}

Snow cover has significant effects on water and heat in freezing and thawing soil. According to the main physical processes of water and heat transfer in snow cover and soil, a cold region snow-soil coupled model was established. Using measured data for seasonal snowmelt, water and heat status, frozen depth, liquid water content and soil temperature were simulated numerically. The simulation results were compared with measured values at corresponding times and locations to verify the reliability and precision of the model. 
With the thawing and freezing of soil, runoff varied greatly. This means seasonal variations in the thawingfreezing process of the soil's active layer played a significant role in the seasonal runoff shift in the Three-River Source Region.

Data availability. The underlying research data can be accessed, although some of the data are not publicly accessible. Because some of the data used in manuscript was collected from the related office of government, some of which can not be visited from outside.

Competing interests. The authors declare that they have no conflict of interest.

Special issue statement. This article is part of the special issue "Innovative water resources management - understanding and balancing interactions between humankind and nature". It is a result of the 8th International Water Resources Management Conference of ICWRS, Beijing, China, 13-15 June 2018.

Acknowledgements. This research is supported by the $\mathrm{Na}$ tional Key Research and Development Program of China (No. 2016YFA0601000) and the Fundamental Research Funds for the Central Universities (No. 2015B20314).

Edited by: Bo Pang

Reviewed by: two anonymous referees

\section{References}

Dingman, S. L.: Physical Hydrology, Prentice-Hall, Old Tappan, NJ, 1994.

Flerchinger, G. N. and Saxton, K. E.: Simulataneous heat and water model of a freezing snow-residue-soil system I. Theory and development, Trans. of ASCE, 32, 565-571, 1989.
Harris, C., Haeberli, W., Mühll, V. D., and King, L.: Permafrost monitoring in the high mountains of Europe: the PACE project in its global context, Permafrost Periglac., 12, 3-11, 2001.

Harris, C., Arenson, L. U., Christiansen, H. H., Etzemuller, B., Frauenfelder, R., Gruber, S., Haeberli, W., Hauck, C., Holzle, M., and Humlum, O.: Permafrost and climate in Europe: monitoring and modelling thermal, geomorphological and geotechnical responses, Earth-Sci. Rev., 92, 117-171, 2009.

Heginbottom, J. A.: Permafrost mapping: a review, Prog. Phys. Geog., 26, 623-642, 2002.

Jorgenson, M. T., Racine, C. H., Walters, J. C., and Osterkamp, T. E.: Permafrost degradation and ecological changes associated with a warming climate in central Alaska, Climatic Change, 48, 551-579, 2001.

McGuire, A. D.: Environmental variation, vegetation distribution, carbon dynamics and water/energy exchange at high latitudes, J. Veg. Sci., 13, 301-314, 2002.

Romanovsky, V. E. and Osterkamp, T. E.: Permafrost: changes and impacts, in: Permafrost Response on Economic Development, Environmental Security and Natural Resources, edited by: Paepe, R. and Melnikov, V., Kluwer Academic Publishers, 297-315, 2001.

Shoop, S. A. and Bigl, S. R.: Moisture migration during freeze and thaw of unsaturated soils: modeling and large scale experiments, Cold Reg. Sci. Technol., 25, 33-45, 1996.

Walker, D. A., Jia, G. J., and Epstein, H. E.: Vegetation-soilthaw-depth relationships along a low-arctic bioclimate gradient, Alaska: synthesis of information from the ATLAS studies, Permafrost Periglac., 14, 103-123, 2003.

Xu, X. Z. and Deng, Y. S.: Experimental research of moisture migration in frozen soil, Science Press, 1991 (in Chinese).

$\mathrm{Xu}, \mathrm{Z}$. X. and Li, J. Y.: Estimating basin evapotranspiration using distributed hydrologic model, J. Hydrol. Eng., 8, 74-80, 2003.

Yin, Z. F., Ouyang, H., and Chen, H.: Simulating Soil Freezing and Thawing of Temperate Desert Ecosystem on the Qinghai-Tibet Plateau, Proc. Environ. Sci., 2, 476-485, 2010. 